\title{
A Theoretical Positioning of Self and Social Identities as Antecedents in Cultural-Experiential Tourism
}

\author{
Atanu Nath \\ Western Norway University of Applied Sciences, Norway \\ atanu.k.nath@hvl.no \\ Parmita Saha \\ Western Norway University of Applied Sciences, Norway \\ parmita.saha@hvl.no
}

Museums are often regarded as a cultural destination, however they stand distinct from other purveyors of culture in that they consciously attempt at a less pronounced social and cognitive dissonance among the audience it covets. In their strife for continuity as an overarching goal, museums by necessity have moved away from being torchbearers of heritage and interpretive centers thereof, to being experiential centers and thus facing challenges associated with a duality of roles. Conscious democratization and integration efforts to draw in the masses require commensurate marketing strategies, while at the same time museums strive to offer an experience that is in effect personal. It is our contention that museums offer a unique and valuable opportunity for theoretical and empirical work in tourism consumer behavior research. To such end, this research reviews the constructs identity seeking (selfidentity), identity projection (social identity) as determinants of motivation in cultural experiential tourism. Motivation is considered along the dimensions of reflective and recreational motivation. A theoretical framework of relationship between identity and motivation to explain pre and post visitation attitude formation and behavioral intention in cultural experiential tourism is proposed, along with methodological notes on pursuant empirical research to validate the framework.

Keywords: self identity, social identity, motivation, behavioral intention, cultural tourism, experiential tourism

https://doi.org/10.26493/2335-4194.10.115-128

\section{Introduction}

Museums have often been regarded as a cultural destination: by definition, a bearer of legacies and heritage. New museologists have regarded museums as social institutions with their share of social, political, and economic influences and biases, and have advocated larger integration with the multi-cultural society (Stam, 1993), arguing they should not be above the concerns of the non-elite (Prentice, 2001). Pearce (1998) states it is not museums' role to be either static or enduring, thus opening itself to the only constant of the outside: change.

Ironically, charges of the museums (and to a greater extent, the arts) being above the concerns of the nonelite may not be their own making, but rather imposed upon them. As Šola (1992) observes, the arts is where the social and cognitive dissonance is most pronounced, and elevating it and showcasing it as to be above the 'common man' and proclaiming art to be for the sake of the arts blunts the edges of the disso- 
nances. Šola (1992) holds society, art historians, and sometimes artists themselves guilty of a collusion in what he views as a self-serving and less discordant, less disconcerting positioning of the arts. If we follow this argument, then the museums can serve their inherent purpose better if they align themselves with the so-called non-elite, or rather more preferably not be segmented along such lines at all. In reality, they continue to do so, especially in recent decades, in contrast to Šola's premise. However, museums are perhaps exceptions in this regard, compared to the other arms of the 'high arts.'

The goal of this research is to propose a framework for positioning self-identity in confluence with social identity as motivators behind participating in cultural and experiential tourism, or rather 'culturalexperiential tourism, as we shall argue in a section to follow, and behavioural intention. However, do museums merit a closer scrutiny from a tourism and consumer perspective, rather than an esoteric one? We believe that they do, precisely because museums as an application area offer an opportunity for a convergence and resolution of theoretical perspectives. Weil (2000) has pointed out that museums have moved on from their oft misperceived role of cemeteries of bric-a-brac to a more visitor-oriented role, accentuating the need for more studies from the consumer perspective, and not museological ones. Sheng and Chen (2012) highlight that museums roles have evolved towards education and recreation from collection, research, and exhibition. These integrative efforts are not new to museums. But because the museums consciously attempt to democratise (perhaps in contrast with other exhibitors and curators of culture, such as art galleries), they are faced with the challenges of the duality of their roles.

Šla (1992) raises two important points: one of identity balance to which the observation above pertains, the need to invent and reinvent oneself, to not box one's identity among one or few segments. The other is that of striving for continuity as a paramount goal in itself, newness of architecture or application of technology serving as effective tools toward achieving this goal. In this regard, museums have gradually moved away from being torchbearers of heritage and interpretive centres thereof, to being experiential cen- tres. The Knut Hamsun centre in the north of Norway, for example, has promoted the Hamsun experience not through exhibiting the life and works of the author, but rather through the interplay of architecture and light. It is by no means a solitary example. A museum as a provider of cultural and experiential tourism must draw a balance between these two primary goals. Prentice (2001) points out that the problem for museums today is no longer re-orientation, but of the oversupply of museums to its catered masses - an effect of renewed and ongoing adaptation. If so, it does not diminish but underscores the need to identify underlying factors toward visitations, without being bogged down into segmentation.

It is precisely because it consciously attempts to do away with segmentation that it holds a special interest in this research. Devoid of segments as a basis of its outreach, we propose self-identity as a primary motivational construct. To be noted, it is not argued here that segmentation has no influence on visitations - it may well have; it is argued that museums have increasingly democratised, which is desirable, but may not have found an alternate construct that can support filling in the void of conscious reliance on demographics. Catering to the notion of self-identity and the social reflection of identity as antecedents are proposed herein to fill such a void.

Furthermore, Falk (1998) had highlighted that human behaviour, in particular museum-going behaviour, cannot and should not be measured by demographic categories alone. Museologists also recognise the need for a multi-disciplinary approach towards attaining knowledge of visitors. Hood (1983) indicated decades ago that psychographic factors such as values, attitudes, perceptions, interests, expectations, and satisfactions are essential for understanding potential and actual visitors. Housen (1987) proposed three dimensions (demographic data, attitudinal information, and developmental situations) for understanding visitor behaviour. Thus, museums occupy a rather singular position in the theoretical spectrum. Conscious democratisation and integration efforts to draw in the masses require commensurate marketing strategies, while museums simultaneously strive to offer an experience that is in effect personal. If we focus on author 
museums, the experience is indeed deeply and often solely personal. Hence, we contend that museums offer a unique and valuable opportunity for theoretical and empirical work in tourism consumer behaviour research.

Behaviour is triggered by many factors (learning, cultural conditioning, social influences, perceptions) yet motives are taken as a starting point for a decision process (Crompton \& McKay, 1997). This research examines an area of cultural tourism - museums - and attempts to forward a conceptual framework positing self-identity as an antecedent of visit motivation and subsequent pre- and post-attitude formation towards behavioural intention.

Based on the discussion thus far, the following research objectives are set forth:

1. To review and explore the presence and validity of identity seeking (self-identity) and identity projection (social identity) as determinants of motivation in cultural-experiential tourism.

2. To propose a theoretical framework of the relationship between identity and motivation to explain behavioural intention in cultural experiential tourism.

\section{Theoretical Review}

On Cultural and Experiential Tourism

Experiential tourism entered the academic consciousness in the early 1990 os with an Australian report highlighting the emergent trend of the experience based domestic traveller (Smith, 2006). Pine and Gilmore (1998) speaks of the experience economy, and defines 'experiential' as a series of related experiences, and creating a portfolio of such. In their view, experiences are different from services in that to an experience deliverer, any economic functions provided are but a stage; the focus is not on making the experience necessarily customised but rather personal and memorable. Experiences are often wrapped around traditional wares, and the authors opine that to reach a stage of added economic value, businesses may need such increasing experiential wrappings. Aside from the goods-andservices business, in the case of tourism, there is forceful argument linking it to experience. In his editorial note, Pizam (2010) rightly surmises that in tourism and hospitality, the quality of both the tangible and intangible services on offer are not often correlated to satisfaction; instead, it is the experience that delivers the desired outcome. It is the creation of a memorable experience that matters.

Can a museum visit be likened to a tourism experience? Some of the outcome variables as consequences of tourism-related visits are denoted by Woodside, Caldwell, and Albers-Miller (2004) as the perceived quality of the visit experience, the satisfaction with activities experienced; intentions to return, post-experience, word-of-mouth, and communications. They are certainly also desirable outcomes for a museum. However, we argue the motivational antecedents leading to a museum visit sets itself apart from a tourism experience. Furthermore, while a museum experience thus may adhere to the idea of creating a memorable experience as a necessity for achieving common satisfactory outcome variables, in our view there is another notable distinction setting it aside as a form of tourism provider. Such being adding economic value is not on a priority list for them, even while catering to the masses. Thus a generic experiential tourism definition may not be the most applicable in exploring antecedents of museum visits. Tung and Ritchie (2011) have conducted a notable study investigating the constituents of memorable tourism experiences; significantly, they have considered factors that lead to the formation and retention of experiences. We agree to this stance, but add that if we are to view museum visits are not similar to other tourism experiences as noted above, then experience formation and retention antecedents are likely to be different as well, despite common outcome variables.

The question then arises whether we can take the cultural as a fork of experiential tourism. Cultural tourism has been dubbed as a sub-set of experiential tourism (Stebbins, 1997), composed of both the search for and participation in experiences of an aesthetic, emotional, intellectual, or psychological nature. It differs from other forms of tourism (i.e. serious leisure), defined as a systematic pursuit of a hobby that may also culminate in a career requiring special skills, knowledge, and experience (Stebbins, 1997) and from casual 
leisure, which is an activity which is defined as an immediate and short-lived pleasurable activity. Furthermore, there is evidence of dichotomy within cultural tourism itself. Richards (2011) classifies travel related to famous authors, painters etc. as the use of creative products; in turn, creativity is proposed as a means to escape 'mass culture tourism,' one of the dichotomous elements.

In this evolving scenario, we can delve into a debate of whether museum visitations now fall within cultural or experiential tourism. Based on the discussion, we argue a nuance may be drawn by renaming this narrower context as a new categorisation - cultural experiential - that is distinct from cultural or experiential by themselves. Experiential tourism has indeed been addressed in the context of culture; Florida (2002) in pursuance and within this theme, mentions a creative class that is a chief target segment of this experiential marketing, a class that, according to him, creates new ideas, technology, and creative content; and 'prefers active, authentic, and participatory experiences which they can have a hand in structuring.' Yet, as we have discussed earlier, this cannot be applicable for museums either, since museums are increasingly not bound to, neither should they be, to any distinct classes.

Instead, we propose that it is now fluid, exhibiting characteristics of both cultural as well as experiential. Following the definition of Kotler and Scheff (1997) of arts or cultural products as those that are visibly and essentially offered to the target market, Prentice (2001) identified that museum displays, plays, and concerts could all be classified as core products within the arts, to be accompanied by additional expected products, such as on-site facilities and support, and augmented products such as venue-related newsletters, lectures or other cultural events on premise, nearby eateries, etc. Today, presence and interaction through social media could be taken as supplants for newsletters. However, Prentice (2001) notably also provides an alternative conceptualisation for experiential tourism, which while retaining the three concentric circles of the product named above, stresses that within cultural exhibits, formal producers such as the museums or the theatres are not the sole creators of the product-based experience, but consumers are also the creators or pro- ducers by dint of their imagination. This observation tallies with the earlier work of Cunnell and Prentice (2000), in which they stated museums and galleries may be initial producers, but the final tourism product is a co-creational effort between the initial producers and the individual tourist. This is especially true when the tourism product is personal in nature. Thus, museums, or galleries, or performance attendances are better classified as cultural experiential, which to be successful need to incorporate imaginings of the visitors as well as allow them to associate with the places, and provide perceptions of authority.

\section{On Choice of Literary Museums as Application Area for Cultural Experiential Tourism}

Jiang and $\mathrm{Xu}$ (2017) assert that there is a close connection between the relevant literature and tourism, but research on it is lacking. They further state it is not essential for literary tourism places to be literally connected to an author, but rather they may be imaged linkages or having an indirect connection to authors' works. Herbert (2001) has worked upon conversion of a literary place into one of literary tourism. He illustrated a two-stage process, in which the tourism manager (or rather, the museum authorities) produces the text, and a second stage where it is interpreted by the literary tourist. This indicates a need for text or supplement that matches or enhances the inner longing and anticipation on the part of the literary visitor.

More significantly, Herbert (2001) has drawn a division among desired qualities of a literary place, namely the 'exceptional' and 'general' qualities of a site. The exceptional qualities include association with the writer, association with settings for stories, association with affective values, nostalgia, memory, symbolism, and the development of literary connections and preservations thereof. The general qualities of a site refer to attractive settings, facilities, and services, location on tourist itinerary, and development as a visitor attraction and access.

These are two quite distinct qualities. Herbert (2001) has referred to the 'diversified literary tourist,' catering for whom has led to a multiplication of literary places. At this juncture, we may hazard a division of our own: one that consists of a dedicated literary tourist, mak- 
ing a pilgrimage of sorts to literary museums, paying homage to the author of his or her subject of affection; versus the 'local attractions' visitor, who may venture to the museum regardless of the depth of familiarity or affection for the writer. It is proposed that the elements of the exceptionalism of a literary place will carry more weight as motivational factors for the former group - 'the literary pilgrim,' while the general qualities will act as motivator for the latter - 'the culture tourist.' The proposed construct of self-identity is posited to fall within the realm of motivator related to exceptionalism; it is hypothesised that is where it shall have potency. However, the presence of the pursuit of self-identity as a construct is not posited to be an exclusive element of the former group. Indeed, it is an exciting prospect if the presence of such a construct was found among the latter, which might indicate a transformative effect taking place among the casual visitor post-visitation.

One of the tenets discussed above is that a museum visit is unlike other tourism experiences due to difference in antecedents of motivation and consequent behaviour. In conjunction, we justify the literary museums as application area for cultural experiential tourism. The next sections will discuss the constructs that we propose as determinants of behavioural intention in the context of literary museum visits and the relationships between the constructs.

\section{Framing Identity in a Cultural Experiential Context}

Prentice (2001) has defined cultural tourism succinctly. He states it as a form of tourism that is 'constructed, proffered and consumed explicitly or implicitly' for cultural appreciation. This appreciation can take the form of the consumption of experiences or for gaining systematic knowledge. As Moscardo and Pearce (1999) note, the consumption of experience demands involvement or an experience of authenticity, whereas Prentice (2001) states that the knowledge gaining through visitations to museums is engaged in for a richer understanding of the culture it represents. Thus, we have evidence of two distinct and divergent motives emerging within the context of cultural tourism. The latter is posited to be a consumption tied to emotion and spirituality by Prentice (2001), echoed by McIn- tosh (1999), who states visits centred on knowledge and richer understanding are more uniquely personal, emotionally charged, and valued: un essence, a personal journey, one which we associate here with the construct (quest for) self-identity herein. Consumption as experience, in contrast, is posited to have a more utilitarian nature. This is the component that Craik (1995) refers to when she identifies cultural tourism as an industry marketing cultural products as cultural experiences to its consumers.

In this research, we instead lean toward partially adopting the views of Taheri, Jafari, and O'Gorman (2014), who have mentioned the construct of cultural capital, consisting of homology or a penchant for the 'elite class' to consume elite culture and vice versa; individualism where the same individual may assume multiple identities in search of self-realisation; and an omnivore-univore perspective.

We began this article with the argument of Šola (1992) about (most) museums' conscious embrace and push towards increased democratisation. Such a position would reject the preponderance of homology as a potent antecedent toward visit behaviour at cultural-experiential destinations such as museums. Prentice (2001) has also hinted at the need to recognise democratisation as essential for the cultural tourism industry, of which museums are a part, in practice. The need for such democratisation negates homology as a formative construct in the context of museums.

We do however find the omnivore-univore stratification offered by Chan and Goldthorpe (2005) to be pertinent; while this view also hinges on social stratification, the classifications are more nuanced in their study. The omnivore-univore perspective posits differentiation and creation of classes with regard to culture consumption that is tied to educational levels and incomes, as well as their social milieu. Thus, we find it a more pragmatic approach in identifying segments and associated motivation classification that may exist in cultural-experiential consumption, a market-forcedriven segmentation, rather than one that emanates from elitism which is actively eschewed by purveyors of such consumption. The omnivore-univore is essentially a socially fused construct, moulded by demographic factors such as education, and income, but 
also concerned with meshing in with its social environment and its elements. We equate this construct with social identity in our research, the influence of which is hypothesised to be more potent in case of the 'culture tourist' as proposed and discussed earlier. Another important distinguishing aspect of the omnivore-univore perspective is that it does not map the social stratification along the elite and the masses regarding cultural consumption; instead, stratification is done based upon the range of cultural consumption: omnivore including high as well as so-called middleand low-brow culture, and the univore strata limited to consumption of only the popular form of culture. Since it bypasses the elite and the masses' binary view of cultural segmentation, this perspective then aligns with our previous argument for museums and their avoidance of segmentation. We adopt this view as a constituent of social identity.

The other aspect of cultural capital as identified by Taheri et al. (2014) is an assumption of multiple identities in search of self-realisation. This is posited as contributing to our construct self-identity, the influence of which is hypothesised to be potent in case of the literary pilgrim' or the dedicated literary tourist identified and discussed in the earlier section.

In addition, we refer to the work of Sparks and Shepherd (1992) on defining identity in relation to the theory of planned behaviour (Ajzen, 1991; Netemeyer, Ryn, \& Ajzen, 1991). We have earlier discussed the work of Biddle, Bank, and Slavings (1987) who have posited a person's self-identity to be a distinct concept from his or her evaluative attitude, which is echoed by Sparks and Shepherd (1992), a view that we have supported. However, Sparks and Shepherd (1992) further argue that any causal link between such self-identity and behaviour may not be entirely independent of attitudinal evaluation. Instead, self-identity is affirmed and bolstered through the performance of certain behaviour. We accept their hypothesis that self-identity is reflected in and influences one's attitude, but would not show an independent influence on behavioural intentions.

As to the definition of self-identity, as Gleason (1983) states, 'Its very obviousness seems to defy elucidation!.' If we take a psychological definition, then self-identity would be akin to what remains consistent through a person's phases of existence, a continuity of his personality, a matter of retaining a 'sameness.' Gleason (1983) finds his support in the words of Wordsworth and D. H. Lawrence, equating identity to an integrity of the self. His paper vacillates between the discussion of both self-identity in the sense mentioned above, and other forms of identity such as political, ethnic, and others. We, however, view these as belonging to a form of social identity. This quest for retaining a consistent thread in one's life, by which one interprets and perhaps anchor the 'self' is our view of self-identity. A behavioural manifestation, such as literary pilgrimage, or museum visit would be a step in the quest of completion and continuation of selfidentity, an iteration in self-actualisation.

Thus, based upon the distinction drawn in the context of cultural capital, we propose two identity constructs leading to two distinct motivational antecedents. The first construct, self-identity leading to motivation, we term as reflective, based upon introspection, and self-actualisation. The second construct, social identity, leading to motivation is termed as 'recreational,' with which behaviour is manifested due to factors other than exceptionalism as previously discussed, a non-individualistic socially mediated driver.

\section{Motivation in Literary Museum Context}

While past research has often given motivation a central role in decision processes, tourism research had a dearth of empirical works on motivation (Lundberg, 1980). This is more evident in the fields of event and holiday tourism (Crompton \& McKay, 1997), and virtually non-existent for author museums, prompting a need for such investigations to fill the perceived literature gap.

Motivation is conceptualised as a dynamic process of internal psychological factors generating a state of disequilibrium, prompting individuals to take actions aimed at resolving said state (Crompton, 1979). Thus identifying and prioritising motives are key to understanding visitors' decision processes. Um and Crompton (1990) suggest that marketing activities can be conducted more effectively if target markets can be delineated based on benefits sought and promotions 
catering to them. It should be noted that while this most certainly applies to event and festival tourism studies, two forms of experiential tourism, the same may not necessarily be said for visitations to author museums. The earlier discussion underlined the museums' conscious and active move away from highly segmented targeting to increase its audience, which holds true for historical museums, and perhaps even more for author museums. Indeed, as has been mentioned, such democratisation is in keeping with the spirit of the institutions as originally envisaged. Thus, we have a dichotomy: museums cannot rely on segmentation for increasing marketing effectiveness; in contrast, their fulfilment of needs is essentially that of the individual. They cater to specific motives of individuals. This dichotomy lies behind the choice to focus on self-identity as a potential motivator for author museums.

Even for individuals, in case of an experiential visit, there are multiple needs at work (Mansfeld, 1992; Nicholson \& Pearce, 2001). The need to interact with family can be one of them (Crompton, 1979); it is not often easy to gather members together at home. Rao (2001) echoes this, emphasising the public good aspect that goes beyond entertainment and revenue generation and one which brings families together in showing their commitment towards the community. The desire for collective cultural enrichment can be another (Crompton \& McKay, 1997). A festival or event can package several elements to cater to individuals within this family collective, each deriving separate benefits from the elements. In contrast, visits to art museums, and more particularly author museums are far more introspective affairs, and the offerings, while still possibly having several elements in its package, are centred around the introspection on the part of the visitor. It is essentially a solitary journey on the part of the traveller, the visitor. This is a further argument for focusing on the search for self-identity as an antecedent in the case of author museums.

There are two types of motivation identified earlier in the serious leisure context: intrinsic and extrinsic. Intrinsic motivation is related to a person's interest in performing activities for his or her own sake: the behaviour is voluntary and absent of external rewards.
In case of intrinsic motivation, people are motivated by reaching desired achievement, knowledge acquisition, desire for pleasure and satisfaction; the deeds by themselves are the intrinsic rewards. In contrast, extrinsic motivations lead to behaviour that is more utilitarian in nature, concerned with achieving a desired outcome. This contrasts with intrinsic motivation, for which engagement in the act is sufficient in itself (Alexandris, Tsorbatzoudis, \& Grouios, 2002). Visitors' cognitive learning, reflective and recreational motivation is associated with their visiting experience and reasons associated with their museum visit (Falk, 2013; Prentice, 2001; Slater, 2007). Taheri et al. (2014) identified recreational and reflective motivation to determine museum visitors' level of engagement. In their study, they have defined reflective motivation as an individual's self and identity projection that is measured with self-expression, self-actualisation, self-image and group attraction. Recreational motivation was associated with enjoyment based enrichment and was measured by self-enjoyment, satisfaction, re-creation and personal enrichment. In light of that, the present study considers the reflective and recreational motivations as determinants of attitude formation and behavioural intention.

\section{Identity, Motivation, Attitude, and Behaviour}

Commensurate to this bi-furcation of identity linked to cultural-experiential tourism, for which we set museums as the context of this research, there is a need to compartmentalise motivations arising out of the assumed identities. Push and pull motivations are a prevalent distinction among motivational perspectives; push relates to individual's own interest(s) in visiting a place, and pull relates to the attractions of a destination itself (Baloglu \& Uysal, 1996). However, in our view, this distinction falls short from an identityseeking perspective, since it does not delve more granularly into what such interests might be. Iso-Ahola and Allen (1982)'s identification and classification of such push and pull factors emanating from intrinsic and extrinsic reasoning for displayed behaviour is also problematic in this respect, since their study was conducted in the context of leisure activity. The psychological 'push' elements in intrinsic as identified 
by Iso-Ahola and Allen (1982) are likely to be separate from those behind visitation behaviour at a museum or other cultural-experiential venue.

Sparks and Shepherd (1992) have linked the construct of self-identity and the sense of belonging to having an influence on behaviour, and Biddle et al. (1985) posit identity as being central to conduct. Biddle et al. (1987) contend that a person's self-identity is conceptually distinct from his or her evaluative attitude in predicting behaviour when the behaviour is nonutilitarian. Thus, whether regarding a non-utilitarian or utilitarian purchase situation, identity is postulated to be a construct in motivating behaviour.

Biddle et al. (1987) have identified three principal streams of thought behind behavioural research; norms or personal standards, preference or attitude, and self-referent identity labelling or concept of self being the three different drivers influencing behaviour. Importantly, they identify that their effects are not overlapping, thus being distinct from each other and, in all likelihood, complementary in predicting behaviour.

Kelly (1985) has linked the experience of art-related attendance to the construction of a self-identity and belonging, which can have significant influence on behaviour (Sparks \& Shepherd, 1992), and be central to conduct (Biddle et al., 1985). Conversely, as identified above, a person's self-identity can be conceptually distinct from his or her evaluative attitude in the prediction of behaviour (a non-utilitarian act) (Biddle et al., 1987). Thus, self-identity can lead to behaviour independent of attitude.

Therefore, there is support for linking identity as a distinct construct to behavioural motivation. This requires a broader understanding of identity, a departure from the discussion has not yet been bound to the realm of a cultural experience and instead is a more generic one. This has been a long-researched construct that has been examined from various perspectives, thus offering no standard definition. Bruner and Kalmar (1998) identified that the self as possessing the characteristics of both inner as well as outer, public and private, innate as well as acquired, and evolved as well as shaped by cultural narratives. Thus, selfidentity itself, while being dubbed 'the self' appears to possess two distinct faces, one that is seen by self one borne out of self-reflection, while the other presented outwards to the society - borne out of a need for self-presentation. If for clarity's sake we are to dub the former as 'self' and the latter as 'social identity' in line with this definition, then they are mutually coexisting constructs, though separate. Falk (2006) dubs identity as 'a placeholder for social and psychological processes revolving around self-definition or self-interpretation.' This further confirms the coexistence of both, psychological processes leading to the formation of self, and social processes leading to the formation of a social identity. A discussion of one cannot ignore the presence of the other.

Bronfenbrenner (1979); Abratt and Kleyn (2012) also state that identity is shaped as a result of the confluence of internal and external social forces. The inseparability of the two is further highlighted by Falk, Heimlich, and Bronnenkant (2008), who stress that identities are malleable and continually constructed, that they are situated in the physical and socio-cultural world, and that each of us maintains numerous identities. Falk et al. (2008) propose that there are great and enduring identities that are innate - which we refer here as the self-identity. The authors refer to the identities that respond to the needs and realities of specific moments and situations as little 'I' identities, or situated identities. This latter set is triggered as responses to social situations, and following our discussion henceforth, learned through individual's family, culture etc. - can be denoted as social identity, equating situated and social identity as namesakes.

Falk (2006) has also discussed the linkage between identity and motivation. In his study, motivation and consequent visitation (manifest behaviour) were defined in the context of visits to museums. However, he underscored that motivation was a product of complex psychological and social constructs, including prior knowledge and experience (social learning), perceived social relationships and expectations, the social and cultural meanings of the institutions in question, as well as personal interests and sense of identity. These last constructs collate to self-identity, as we have introduced before, and the previous constructs constitute the social dimension of identity. Thus, we argue the 
two constructs self and social identity will lend themselves to influencing visitation or participation motivation in a non-utilitarian scenario (as in the case of a cultural or experiential event).

To extend this premise, in a utilitarian or transaction dominated scenario such as consumer purchase, the two constructs self and social identity will lend themselves to influencing 'user/customer engagement,' the counterpart to individual behaviour regards to experiential consumption. The latter supposition denotes that self and social identities no longer remain constructs solely within experiential or nontransactional realms, but can be considered as possible antecedents of participant engagement in transactions - where the self and social identity will converge for each of the individual parties involved. However, in this transactional realm, at least one party engages as part of a larger whole, the corporate - a congregation of the individuals taking part in the transaction on its behalf. This would imply that this congregation or collective resulting in the corporate identity will show a reflection of the social and self-identity characteristics of its cogs. A more in-depth examination of this premise is, however, beyond the scope of this paper.

\section{Attitude and Behavioural Intentions}

Attitude is described as a person's continuing or longlasting cognitive evaluation, which could be favourable or unfavourable, and action tendencies toward some object or event (Ajzen, 1991; Decrop, Pizam, \& Mansfeld, 2000). Theoretically, attitude consists of three components: cognitive, affective and conative or behavioural component. The cognitive component related to evaluation that form an attitude, the affective component is psychological responses explaining the preferences, and the conative or behavioural component is the indication of future intention. Over the period of time attitudes were formed and stay consistent (Schiffman \& Kanuk, 2004). In the past, research attitude was identified as a basis of motivation and predicting behaviour (Gnoth, 1997).

Behavioural intentions indicate desirable behaviours that visitors expect they will perform in the future. Many studies conducted in the tourism research area have identified several antecedents of behavioural intention, e.g. (Lam \& Hsu, 2004, 2006; So Yon Lee, Petrick, \& Crompton, 2007; Yuan \& Jang, 2008). In the previous research, behavioural intention was measured considering several dimensions: positive word of mouth, recommendation to others, repurchase intention, willingness to pay more (Cronin \& Taylor, 1992; Zeithaml, Berry, \& Parasuraman, 1996).

According to the theory of planned behaviour (Ajzen, 1991), a person's behaviour is influenced by his/her behavioural intention and behavioural intention is determined by his/her attitude, subjective norms and perceived behavioural control. In this model, motivation is incorporated to behavioural intention since behavioural intention is explained by the efforts and actions the individual will take to perform a particular behaviour. Intention to perform a particular act will not occur until an individual is sufficiently motivated and has the desire to perform said particular action (Bagozzi, 1992). Together with the theory of planned behaviour, several studies also have tested relations between attitude and behavioural intention in various research areas. According to Baker and Crompton (2000), in order to understand visitors' future behavioural intention, it is necessary to include measures of their attitude.

The different factors influencing the choice of behaviour have also been studied in both the Theory of Reasoned Action and the Theory of Planned Behaviour, according to which there are reasons behind the choices made. The theory of planned behaviour (т Рв) was derived from the theory of reasoned action developed by Ajzen and Fishbein $(1975,1977)$ to investigate the different factors behind behavioural choices. The model posits that behaviour is anteceded by the three kinds of consideration: behavioural beliefs, normative beliefs and control beliefs. Likely behavioural outcomes and the evaluation of such outcomes are defined as behavioural beliefs that produce a favourable or unfavourable attitude toward the behaviour. Normative belief is defined as a belief about the normative expectations and motivation to obey; with these expectations producing the perceived social pressure or subjective norms as a result. Control belief is defined as the presence of factors that may facilitate or obstruct the performance of the behaviour and the perceived 
control of these factors, which give rise to perceived behavioural control. The formation of a behavioural intention is influenced by attitudes towards behaviour, subjective norms, and the perception of behavioural control.

In the Theory of Reasoned Action (TRA), Ajzen and Fishbein (1977)'s assumption was the people engage in rational behaviour and weigh the consequences of any action they might take or choice they make. In the TRA model, behaviour is anteceded by intention to perform the behaviour. Such intention again is pointed out to be a result of two components, which are the subjective norms and attitudes towards a certain behaviour. The model predicts that attitude will be determined by salient beliefs held by the subject regarding whether the performance of the behaviour will result in a desired or given outcome. A subjective norm is defined as a normative belief arising out of subject's referents' advice. It also includes the subject's motivation or the degree of willingness to consider such advice as a moderating variable.

\section{Research Model, Conceptualisation, and Proposed} Hypotheses for Further Research

Following the previous literature discussions, the present study proposes a conceptual model to be tested in a literary museum context in which the proposition is that self-identity and social identity respectively influence visitors' reflective and recreational motivation formation. Both reflective and recreational motivation directly affect visitors' attitude, and attitude influences their behavioural intention. In this research context, behavioural intentions will be measured through positive word of mouth, recommendation to others, and intention to revisit.

The proposed hypotheses for further study as a next step in the research are posited as follows:

1. Self-identity has a direct relationship with reflective motivation formation.

2. Social identity has a direct relationship with recreational motivation formation.

3. Reflective motivation influences attitude towards the literary museum visit.
4. Recreational motivation influences attitude towards the literary museum visit.

5. Attitude influences visitors' pre- and post-visit behavioural intentions.

The hypotheses are illustrated in the following relational diagram.

\section{Research Direction, Methodological Notes for Empirical Research, and Expected Contribution}

This article and its proposed model intends to be delimited to cultural experiential tourism, and author museums in particular, as the application area. The reasoning is twofold. Authors are more easily reachable and relatable; paintings are not (at least not to the researcher, indubitably a personal shortfall). Furthermore, it is hazarded that the tendency to support arts for the sake of the arts alone is perhaps more prominent in the fields of painting or performance arts or such, in comparison to writing. With an author, whether successful by common measures or through the eyes of time, his or her relationship with the reader would almost in all cases be an introverted one, aiding a personal quest, in turn falling more in the realm of the proposed constructs of self-identity and ensuing reflective motivation. An exhibition at a gallery is no such affair. As such, it is viewed that the more pronounced effect of self-identity on visitation, if there be one, will be ascertainable at author museums compared to art galleries, for example.

It is our view that any ensuing empirical research to ascertain the veracity of constructs and their relationships in the proposed гм в model (Figure 1) should employ a mixed method approach, and should include

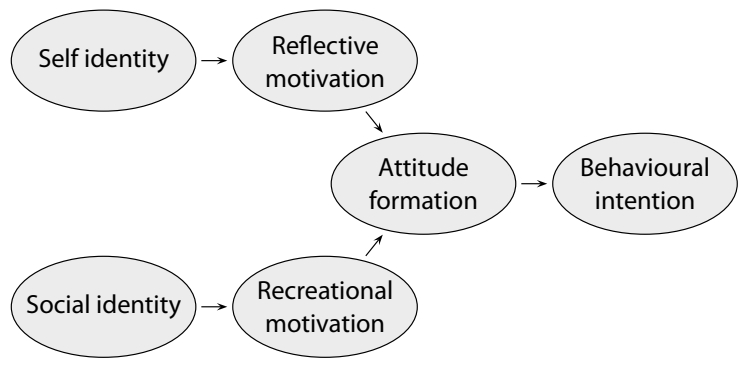

Figure 1 Proposed Identity-Motivation-Behavior (IM B) Model 
Table 1 Conceptualisations of the Variables in Research Model

\begin{tabular}{|c|c|c|}
\hline Variables & Operationalisation and Measurement criteria & References \\
\hline Self-identity & $\begin{array}{l}\text { Self-definition, self-interpretation. Interpreted as a distinct } \\
\text { concept from a person's evaluative attitude, aspiration towards } \\
\text { integrity of the self, self-actualising quest for retaining a con- } \\
\text { sistent thread in one's life, by which one interprets and perhaps } \\
\text { anchors the 'self.' Viewed as leading to Reflective motivation. } \\
\text { Typified by an initial three types of identity-based visitors: ex- } \\
\text { plorers, expert/pilgrims, spiritual travellers. }\end{array}$ & $\begin{array}{l}\text { Falk et al. (2008), Falk (1998, 2006), } \\
\text { Biddle et al. (1987), Sparks and Shep- } \\
\text { herd (1992) }\end{array}$ \\
\hline Social identity & $\begin{array}{l}\text { The omnivore cultural consumer with which stratification is } \\
\text { done based upon a broad range of cultural consumption, rather } \\
\text { than only the popular culture. Typified by an initial two types } \\
\text { of identity-based visitors: facilitators, experience seekers. }\end{array}$ & $\begin{array}{l}\text { Falk (2006), Falk et al. (2008), Taheri et } \\
\text { al. (2014), Chan and Goldthorpe (2005) }\end{array}$ \\
\hline $\begin{array}{l}\text { Reflective } \\
\text { motivation }\end{array}$ & $\begin{array}{l}\text { Individual's self and identity related drive Reflective Motivation } \\
\text { will be measured according to visitors' self-actualisation, self- } \\
\text { image, self-expression. }\end{array}$ & $\begin{array}{l}\text { Falk et al. (2008), Goulding (2000), } \\
\text { Slater \& Armstrong (2010), Taheri et al. } \\
(2014)\end{array}$ \\
\hline $\begin{array}{l}\text { Recreational } \\
\text { motivation }\end{array}$ & $\begin{array}{l}\text { Individual's enjoyment based enrichment. Recreational moti- } \\
\text { vation will be measured according to visitors' Self-enjoyment, } \\
\text { Satisfaction and Recreation. }\end{array}$ & $\begin{array}{l}\text { Falk et al. (2008), Packer (2006), Taheri } \\
\text { et al. (2014) }\end{array}$ \\
\hline Attitude & $\begin{array}{l}\text { A learned predisposition to respond in a consistently } \\
\text { favourable or unfavourable manner with respect to a given } \\
\text { object (Ajzen \& Fishbein, 1975, 1977). Psychological tendencies } \\
\text { expressed by the positive or negative evaluations of visitors. }\end{array}$ & $\begin{array}{l}\text { Lam and Hsu (2006), Song, You, } \\
\text { Reisinger, Lee, and Lee (2014) }\end{array}$ \\
\hline $\begin{array}{l}\text { Behavioural } \\
\text { intention }\end{array}$ & $\begin{array}{l}\text { Desirable behaviours that visitors expect they will perform in } \\
\text { the future. Behavioural intentions will be measured through } \\
\text { positive word of mouth, recommendation to others and revisits } \\
\text { to festival. }\end{array}$ & Zeithaml et al. (1996) \\
\hline
\end{tabular}

the parsing of visitor reviews left at and about the museums, as well as primary data collected using surveys. Two primary sources can be used for the qualitative elements of the data collection: (a) the visitor books maintained at the museums and centres, which hold considerable amounts of remarks left; and (b) remarks and observations left on social media by visitors, specifically on sites such as tripadvisor.com. A content analysis of the reviews and observations using Nvivo can help identify and categorise factors into nodes, which should be analysed to find their alignment with proscribed factors. This can further the help development of an item scale for subsequent measurement and validation of the constructs and the hypothesised relationships.

Several hypotheses have been proposed in this paper to test a research model in the context of visitors' museum visits. A quantitative research approach is deemed appropriate to test the research model and the proposed hypotheses. The constructs identified in the research model will be measured with multiple scale items In line with previous research and following results obtained from the qualitative study as mentioned above. A survey will be developed, and data will be collected from author museums in Norway.

The proposed conceptual model is to be tested in the literary museum context to determine the visitors' behavioural intention in a follow up empirical study. This may create the opportunity for further research in a cultural and experiential context. Based on the motivation attitude behaviour model, the present study incorporated the constructs of self and social identity as determinants of motivation and attitude formation, contributing to the extant literature by establishing a relationship between identity and motivation and attitude formation. Furthermore, the present 
study considers reflective and recreational motivation as two dimensions to measure motivation in the literary museum context, which has not been sufficiently explored in previous research in a cultural and experiential tourism context.

It is important for the museum authorities to understand the visitors' experience related to museum visits and their motivation and behavioural intentions. The conceptualisation and expected results from an empirical study will help them understand who is visiting their museum, what their needs and motives are, and their experience regarding the museum visit. Understanding those phenomenon will help museum authorities to segment their market without compromising the democratisation principle as espoused by Šla (1992), which is necessary in order to not remain static. It may help them understand how better to satisfy different types of visitors following their motivational and identity related needs and what makes them spread positive word of mouth and their revisit intention.

\section{References}

Abratt, R., \& Kleyn, N. (2012). Corporate identity, corporate branding and corporate reputations: Reconciliation and integration. European Journal of Marketing, 46(7/8), 1048-1063.

Ajzen, I. (1991). The theory of planned behavior. Organizational Behavior and Human Decision Processes, 50 (2), 179-211.

Ajzen, I., \& Fishbein, M. (1975). Belief, attitude, intention and behavior: An introduction to theory and research. Reading, m A: Addison-Wesley.

Ajzen, I., \& Fishbein, M. (1977). Attitude-behavior relations: A theoretical analysis and review of empirical research. Psychological Bulletin, 84(5), 888-918.

Alexandris, K., Tsorbatzoudis, C., \& Grouios, G. (2002). Perceived constraints on recreational sport participation: Investigating their relationship with intrinsic motivation, extrinsic motivation and amotivation. Journal of Leisure Research, 34(3), 233-252.

Bagozzi, R. P. (1992). The self-regulation of attitudes, intentions, and behavior. Social Psychology Quarterly, 55(2), 178-204.

Baker, D. A., \& Crompton, J. L. (200o). Quality, satisfaction and behavioral intentions. Annals of Tourism Research, 27(3), 785-804.
Baloglu, S., \& Uysal, M. (1996). Market segments of push and pull motivations: A canonical correlation approach. International Journal of Contemporary Hospitality Management, 8(3), 32-38.

Biddle, B. J., Bank, B. J., \& Slavings, R. L. (1987). Norms, preferences, identities and retention decisions. Social Psychology Quarterly, 50(4), 322-337.

Biddle, B. J., Bank, B. J., Anderson, D. S., Hauge, R., Keats, D. M., Keats, J. A., ... Valantin, S. (1985). Social influence, self-referent identity labels, and behavior. Sociological Quarterly, 26(2), 159-185.

Bronfenbrenner, U. (1979). The ecology of human development: Experiments by nature and design. American Psychologist, 32, 513-531.

Bruner, J., \& Kalmar, D. A. (1998). Narrative and metanarrative in the construction of self. In M. D. Ferrari \& R. J. Sternberg (Eds.), Self-awareness: Its nature and development (pp. 308-331). New York, Ny: Guilford Press.

Chan, T. W., \& Goldthorpe, J. H. (2005). The social stratification of theatre, dance and cinema attendance. Cultural Trends, 14(3), 193-212.

Craik, J. (1995). Are there cultural limits to tourism? Journal of Sustainable Tourism, 3(2), 87-98.

Crompton, J. L. (1979). Motivations for pleasure vacation. Annals of Tourism Research, 6(4), 408-424.

Crompton, J. L., \& McKay, S. L. (1997). Motives of visitors attending festival events. Annals of Tourism Research, 24(2), 425-439.

Cronin, J. J., \& Taylor, S. A. (1992). Measuring service quality: A reexamination and extension. Journal of Marketing, 56(3), 55-68.

Cunnell, D., \& Prentice, R. (200o). Tourists' recollections of quality in museums: A servicescape without people? $\mathrm{Mu}$ seum Management and Curatorship, 18(4), 369-39o.

Decrop, A., Pizam, A., \& Mansfeld, Y. (2000). Consumer behavior in travel and tourism. New York, NY: The Haworth Hospitality Press.

Falk, J. H. (1998). Visitors - who does, who doesn't, and why (why people go to museums). Museum News, 77(2), 38 43.

Falk, J. H. (2006). An identity-centered approach to understanding museum learning. Curator: The Museum Journal, 49(2), 151-166.

Falk, J. H. (2013). Understanding visitors' motivations and learning. In I. Lundgaard Braendolt \& J. T. Jensen (Eds.), Museums social learning spaces and knowledge producing processes (pp. 106-127). Copenhagen, Denmark: Danish Agency for Culture.

Falk, J., Heimlich, J., \& Bronnenkant, K. (2008). Using iden- 
tity-related visit motivations as a tool for understanding adult zoo and aquarium visitors' meaning-making. $\mathrm{Cu}$ rator: The Museum Journal, 51(1), 55-79.

Florida, R. (2002). The rise of the creative class: And how it's transforming work, leisure, community and everyday life. New York, Ny: Basic Books.

Gleason, P. (1983). Identifying identity? A semantic history. The Journal of American History, 69(4), 910-931.

Gnoth, J. (1997). Tourism motivation and expectation formation. Annals of Tourism Research, 24(2), 283-304.

Goulding, C. (200o). The museum environment and the visitor experience. European Journal of Marketing, 34(3/4), 261-278.

Herbert, D. (2001). Literary places, tourism, and the heritage experience. Annals of Tourism Research, 28(2), 312-333.

Hood, M. (1983). Staying away: Why people choose not to visit a museum. Museum News, 61(4), 50-57.

Housen, A. (1987). Three methods for understanding museum audiences. Museum Studies Journal, 2(4), 41-49.

Iso-Ahola, S. E., \& Allen, J. R. (1982). The dynamics of leisure motivation: The effects of outcome on leisure needs. Research Quarterly for Exercise and Sport, 53(2), 141-149.

Jiang, L., \& Xu, H. (2017). The growth of literary places in ancient town tourism destinations: Based on the theories of Bourdieu, Danto and Dickie. Journal of Tourism and Cultural Change, 15(3), 213-228.

Kelly, R. (1985). Museums as status symbols 2: Obtaining a state of having been there. In R. Belk (Ed.), Advances in non-profit marketing (pp. 1-38). Greenwich, CT: JA I Press.

Kotler, P., \& Scheff, J. (1997). Standing room only: Strategies for marketing the performing arts. Boston, M A: Harvard Business School Press.

Lam, T., \& Hsu, C. H. C. (2004). Theory of planned behavior: Potential travelers from China. Journal of Hospitality \& Tourism Research, 28(4), 463-482.

Lam, T., \& Hsu, C. H. C. (2006). Predicting behavioral intention of choosing a travel destination. Tourism Management, 27(4), 589-599.

Lundberg, D. E. (1980). The tourist business. Boston, MA: Cв I Publishing.

Mansfeld, Y. (1992). From motivation to actual travel. Annals of Tourism Research, 19(3), 399-419.

McIntosh, A. J. (1999). Into the tourist's mind: Understanding the value of the heritage experience. Journal of Travel \& Tourism Marketing, 8(1), 41-64.

Moscardo, G., \& Pearce, P. L. (1999). Understanding ethnic tourists. Annals of Tourism Research, 26(2), 416-434.

Netemeyer, R., Ryn, M. Van, \& Ajzen, I. (1991). The theory of planned behavior. Organizational Behavior and Human Decision Processes, 50(2), 179-211.

Nicholson, R. E., \& Pearce, D. G. (2001). Why do people attend events: A comparative analysis of visitor motivations at four South Island events. Journal of Travel Research, 39(4), 449-46o.

Packer, J. (2006). Learning for fun: The unique contribution of educational leisure experiences. Curator: The Museum Journal, 49(3), 329-344.

Pearce, S. (1998). Objects in the contemporary construction of personal culture: Perspectives relating to gender and socio-economic class. Museum Management and Curatorship, 17(3), 223-241.

Pine, J., \& Gilmore, J. H. (1998). Economy leadership when there is o one to ask? Welcome to the experience economy cost systems putting the enterprise into the enterprise system. Harvard Business Review, 76(4), 97-105.

Pizam, A. (2010). Creating memorable experiences. International Journal of Hospitality Management, 29(3), 343.

Prentice, R. (2001). Experiential cultural tourism: Museums \& the marketing of the new romanticism of evoked authenticity. Museum Management and Curatorship, 19(1), 5-26.

Rao, V. (2001). Celebrations as social investments: Festival expenditures, unit price variation and social status in rural India. Journal of Development Studies, 38(1), 71-97.

Richards, G. (2011). Creativity and tourism: The state of the art. Annals of Tourism Research, 38(4), 1225-1253.

Schiffman, L. G., \& Kanuk, L. L. (2004). Consumer behaviour (8th ed.). Englewood Cliffs, NJ: Prentice-Hall.

Sheng, C. W., \& Chen, M. C. (2012). A study of experience expectations of museum visitors. Tourism Management, 33(1), 53-6o.

Slater, A. (2007). 'Escaping to the gallery:' Understanding the motivations of visitors to galleries. International Journal of Nonprofit \& Voluntary Sector Marketing, 12, 149-162.

Slater, A., \& Armstrong, K. (2010). Involvement, Tate, and me. Journal of Marketing Management, 26(7/8), 727-748.

Smith, W. L. (2006). Experiential tourism standards: The perceptions of rural tourism providers. International Journal of Services and Standards, 2(3), 1-23.

So Yon Lee, Petrick, J. F., \& Crompton, J. (2007). The roles of quality and intermediary constructs in determining festival attendees' behavioral intention. Journal of Travel Research, 45(4), 402-412.

Šola, T. (1992). The future of museums and the role of museology. Museum Management and Curatorship, 11(4), 393400.

Song, H., You, G., Reisinger, Y., Lee, C., \& Lee, S. (2014). 
Behavioral intention of visitors to an Oriental medicine festival? An extended model of goal directed behavior. Tourism Management, 42, 101-113.

Sparks, P., \& Shepherd, R. (1992). Self-identity and the theory of planned behavior? Assesing the role of identification with 'green consumerism.' Social Psychology Quarterly, 55(4), 388-399.

Stam, D. C. (1993). The informed muse: The implications of 'the new museology' for museum practice. Museum Management and Curatorship, 12(3), 267-283.

Stebbins, R. A. (1997). Identity and cultural tourism. Annals of Tourism Research, 24(2), 450-452.

Taheri, B., Jafari, A., \& O'Gorman, K. (2014). Keeping your audience: Presenting a visitor engagement scale. Tourism Management, 42, 321-329.

Tung, V. W. S., \& Ritchie, J. R. B. (2011). Exploring the essence of memorable tourism experiences. Annals of Tourism Research, 38(4), 1367-1386.

Um, S., \& Crompton, J. L. (1990). Attitude determinants in tourism destination choice. Annals of Tourism Research, $17(3), 432-448$.
Weil, S. E. (2000). Transformed from a cemetery of bric-abrac. In B. Sheppard (Ed.), Perspectives on outcome based evaluation for libraries and museums (pp. 4-15). Washington, DC: Institute of Museum and Library Services.

Woodside, A. G., Caldwell, M., \& Albers-Miller, N. D. (2004). Broadening the study of tourism. Journal of Travel and Tourism Marketing, 17(1), 1-6.

Yuan, J., \& Jang, S. (2008). The effects of quality and satisfaction on awareness and behavioral intentions: Exploring the role of a wine festival. Journal of Travel Research, 46(3), 279-288.

Zeithaml, V. A., Berry, L. L., \& Parasuraman, A. (1996). The behavioral consequences of service quality. Journal of Marketing, 6o(2), 31-46.

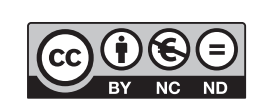

This paper is published under the terms of the Attribution- NonCommercial-NoDerivatives 4.0 International (CC B Y-NC-ND 4.0) License. 